\title{
Analysis of Reproductive Disorders of Cats and Means Used to Correct Them
}

\author{
O.A. Stolbova \\ Candidate of Veterinary Sciences, \\ Assistant Proffesor \\ FSBEI HE Northern Trans-Ural SAU, \\ Tyumen, Russia \\ e-mail: stolbovaoa@gausz.ru
}

\author{
L.N. Skosyrskikh \\ Candidate of Veterinary Sciences, Assistant Professor \\ FSBEI HE Northern Trans-Ural SAU, \\ Tyumen, Russia \\ e-mail: skosyrskyshln@gausz.ru
}

\author{
A.V. Kruglov \\ Postgraduate student \\ FSBEI HE Northern Trans-Ural SAU, \\ Tyumen, Russia \\ e-mail: arinka.120893@yandex.ru
}

\begin{abstract}
The research work was carried out in the period from 2014 to 2018 in the city of Tyumen. In this period 3.237 cats of different breeds and ages were examined. The investigated reproductive disorders were found in 389 cats. It was established that these disorders are widespread in Tyumen and their percentage ranges from 12.02 to \pm 0.195 Purulent endometritis was most often observed in the following breeds: Mestizo - 32.89\% of cases, Scottish fold - 25.00\%, British shorthair - 14.47\%, Abyssinian $7.89 \%$. Cystic ovarian formations were recorded in Mestizos $46.56 \%$, British short-haired - $21.37 \%$, Scottish folds - $18.32 \%$, Sphynxes - 7.63\%. Tumors of mammary glands were found in cats of such breeds as Mestizo - 40.00\%, Sphinx - 23.63\%, Persian $14.54 \%$, Siamese $-14.50 \%$, Abyssinian $-7.27 \%$. The predisposition of cats to purulent endometritis has increased in the following age groups: $11.84 \%$ from 4 to 5 years old, $11.84 \%$ from 5 to 6 years old, and $10.52 \%$ from 7 to 8 years old. $11.45 \%$ of cats from 2 to 3 years old had predisposition to the ovarian cysts: $10.68 \%$ of cats were at the age ranging from 3 to 4 years old; $11.45 \%$ were from 4 to 5 years old; $11.45 \%$ were cats from 5 to 6 years and $12.21 \%$ from 6 to 7 years old. Tumors of mammary glands were registered more often in the age groups from 8 to 9 years old and amounted to $12.72 \%$; from 9 to 10 years old this number comprised 12.72\%; and over 10 years old it was $18.18 \%$. To treat diseases or disorders of the reproductive system organs of cats, the gestagenic drugs produced either in Russia or abroad are used. In the Russian pharmaceutical market there are 33 gestagenic drugs. The share of domestic producers is $91 \%$, which is equal to 92 items and the share of foreign producers is 9\%, which is 9 items.
\end{abstract}

Key words-cats, uterus, ovary, reproductive organs disorders or diseases, medicines

\section{INTRODUCTION}

In the Russian Federation over the past few years the number of small domestic animals with reproductive pathology has increased significantly and ranges from 10$20 \%$. $[8,9,13]$. It is known that the polycyclicity of cats increases the risk of developing reproductive pathologies in comparison with dogs. Some authors state the reflex ovulation mechanism in cats [2-4, 11]. The following signs are important for the research: the pathognomatism of clinical signs of pyometra in cats, the real value of laboratory studies and anamnestic data in the diagnosis of this disease, as well as the possibility of diagnosing subclinical flow of pyometers. [13-15]

Reproductive pathologies are considered by many authors as part of a single pathological process, which is based on the disorders of hormonal function of ovaries: cystic glandular endometrial hyperplasia, chronic endometritis, pyometra, cystic ovary formations, breast tumors. [2, 5, 6, 12, 13].

To regulate sexual heat of females of small domestic animals with the purpose of suppression of its behavioral manifestations, as a rule, hormonal contraceptive drugs are used. When an animal is prescribed hormonal drugs for the purpose of correcting behavior (suppressing libido), the veterinarian should take into account the therapeutic potential of a drug and contraindications to its use indicated in the CDS. To eliminate the behavioral manifestations associated with the sexual heat of cats, which is extremely important for those who have cats at homes, the most widely used methods have been the delay or prevention of estrus with the help of hormonal gestogen-containing drugs. $[1,8,9,10]$

Therefore, studies of pedigree and age predispositions to reproductive disorders in cats remain relevant and will make it possible to timely detect the causes and development of disease in latent flow and subsequently apply modern methods of diagnosis, treatment and prevention of these diseases.

\section{MATERIALS AND METHODS OF RESEARCH}

The purpose of this research was to elucidate the current situation with the reproductive diseases in cats and means for their correction. 
Materials and methods of research. The research was carried out in the period from 2014 to 2018 on the basis of the Department of Non-Communicable Diseases of Agricultural Animals of the Institute of Biotechnology and Veterinary Medicine of Northern Trans-Ural State Agricultural University, veterinary clinics of the city of Tyumen and veterinary pharmacies.

3,237 cats of different breeds and age were examined during the research. The diagnosis was made on the basis of anamnesis, clinical signs of lesions of genital organs (discharge from the external genitalia, increased abdominal volume, etc.) and functional disorders of sexual cycle, as well as ultrasonography and diagnostic laparotomy. The analysis of the market of gestagenic drugs was carried out in veterinary pharmacy organizations. The statistical analysis was carried out basing on the age and breed.

\section{RESULTS AND DISCUSSIONS}

The analysis of the obtained results showed that out of 3,237 animals examined, $389(12.02 \pm 0.195 \%)$ animals had the pathology of reproductive system and mammary glands. Purulent endometritis, cystic ovarian formations, breast tumors, pathological births, intrauterine death were the most common diseases.

In the course of breed predisposition analysis among cats the following breeds were identified having reproductive system diseases: British shorthair, Mestizo, Scottish fold, Sphinx, Persian, Abyssinian, Siamese, Maine Coon (Fig.1).

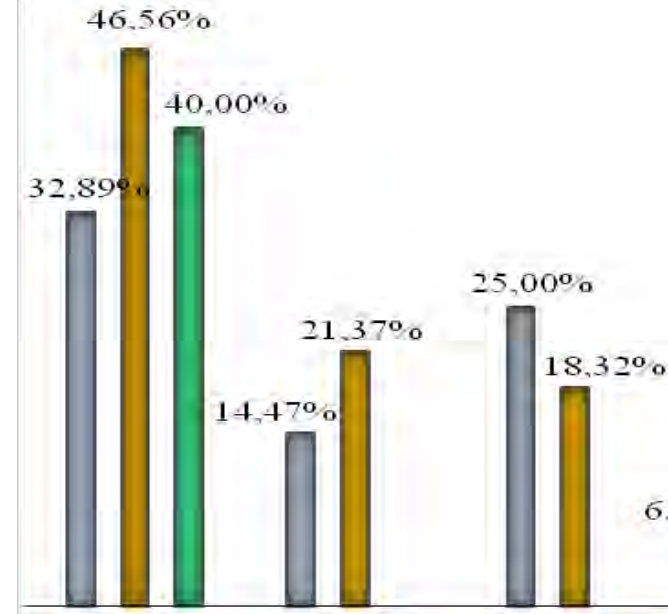

Mestizo British shorthair; Scottish fold;

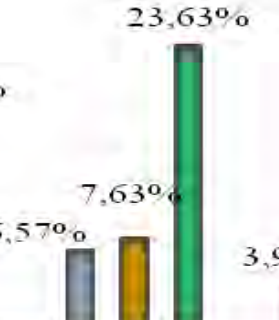

Sphinx;

$$
1+54 \%
$$

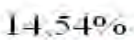

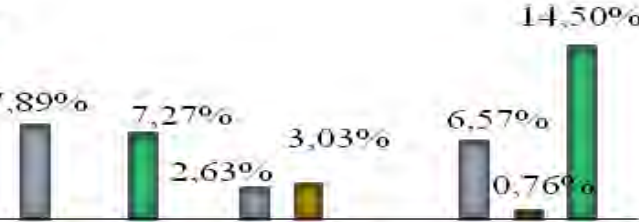

Abyssinian;

Siamese purulent endometritis ncystic ovarian formations breast tumors
Fig.1 The diseases of reproductive system in cats

The largest number of cystic ovarian formations was diagnosed in cats of Mestizo breed - 46.56\%, British shorthaired cats - $21.37 \%$, Scottish fold cats - 18.32\%; purulent endometritis in cats of Mestizo breed - 32.89\%, Scottish fold cats $-25.0 \%$, British shorthair cats $-14.47 \%$, Abyssinian cats $7.89 \%$; breast tumors in cats of Mestizo breed - 40.0\%, Sphinx cats- $23.63 \%$, Persian cats $-14.54 \%$ and Siamese cats $-14.5 \%$.

The smallest number of cases of cystic formations was recorded among Sphinxes - 7.63\%, Maine Coons 3.03\%, Persians - 2.29\% and Siamese cats $0.76 \%$; purulent endometritis in Sphinxes - 6.57\%, Persians - 3.94\%, Maine Coons $-2.63 \%$.

The study of the age-related predisposition of cats to reproductive diseases showed that purulent endometritis occurs at the age from 6 months to 1 year - 3.94\%, from 1 to 2 years old $-9.21 \%$ from 2 to 3 years old $-7.89 \%$, from 3 to 4 years old- $9.21 \%$, from 4 to 6 years old $-11.84 \%$, from 6 to 7 years old $-7.89 \%$, from 7 to 8 years old $-10.52 \%$, from 8 to 9 years old $-9.21 \%$, form 9 to 10 years old $-6.57 \%$, and over 10 years $-9.21 \%$ (Fig. 2 ). 


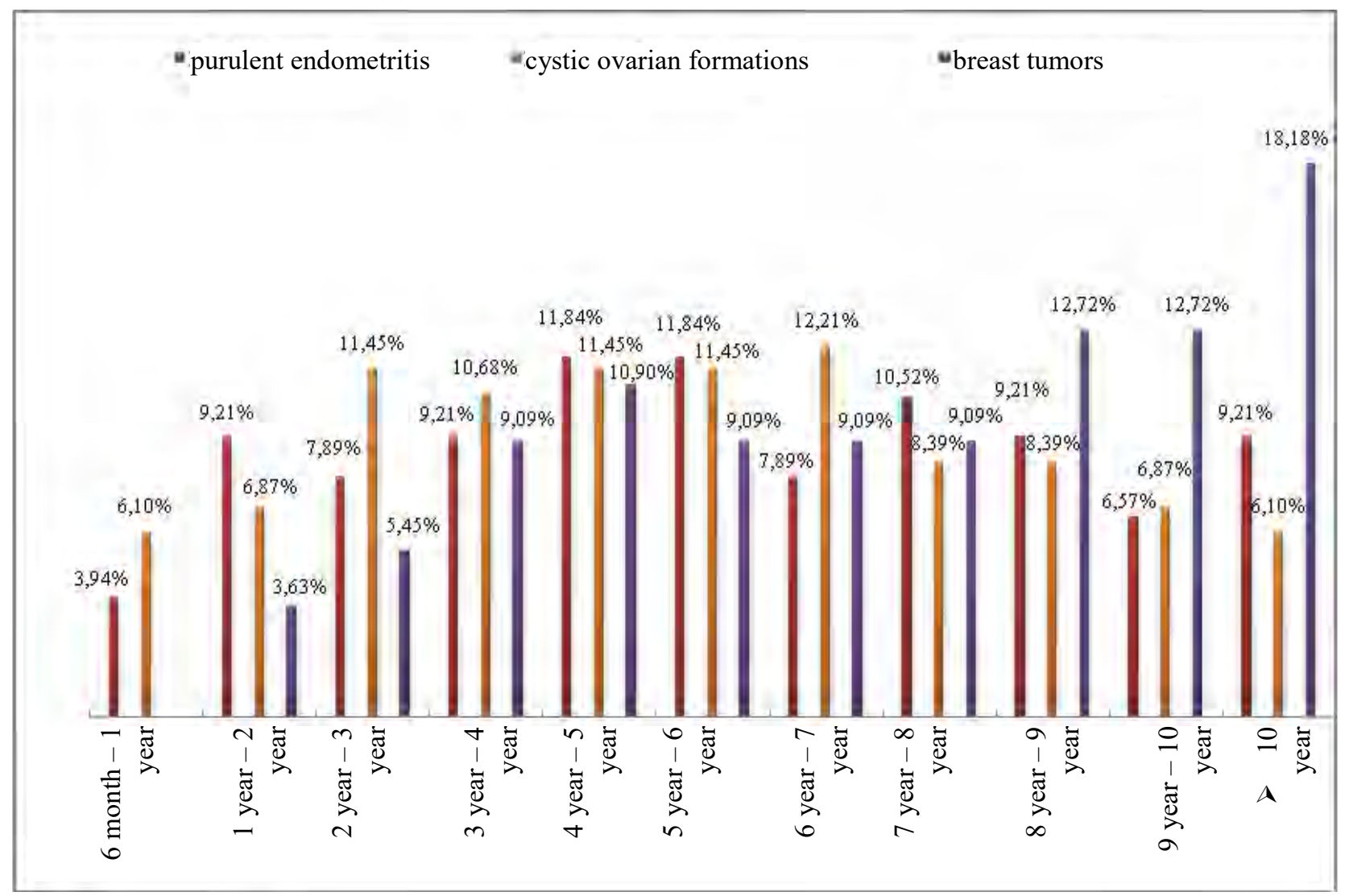

Fig. 2 Age-related predisposition of cats to reproductive diseases

Fig. 2 shows that the greatest number of cases of cystic ovarian formations were registered in cats aged 3 to 4 years old $-10.68 \%, 4$ to 5 years old $-11.45 \%$, and 6 to 7 years old $12.21 \%$. The smallest number of cases was registered from 6 months to 1 year and in animals older than 10 years is $6.1 \%$.

The analysis of the development of breast tumors showed that older animals, namely older than 10 years old (18.18\%), were included in this category. The smallest number of cases of mammary gland neoplasms was registered in cats from 1 to 2 years old $(3.63 \%)$.

Russian market is saturated with such drugs as antimicrobial agents, uroantipeptics, hormones, etc., which are used to treat reproductive system diseases in cats. In this article a special attention is paid to the specific therapy, i.e. hormonal, in particular gestagenic drugs. As a result of the analysis of the proposed drugs in the Russian pharmaceutical market, it was found that out of the proposed 117 hormonal drugs 33 are gestagenic hormones. Out of this number 29 items are produced in Russia (88\%) and 4 are produced abroad (12\%) (Fig. 3).

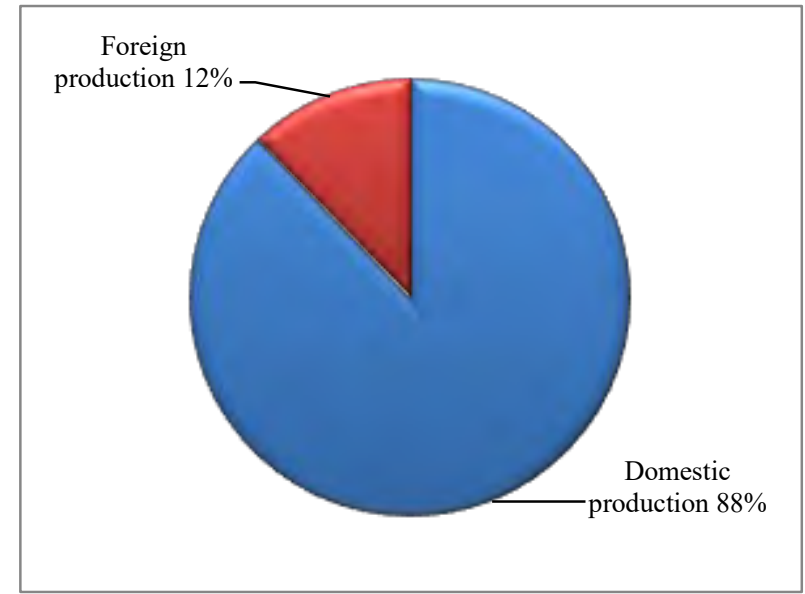

Fig.3. Share of domestic and foreign drugs on Russian market

Foreign hormonal drugs are produced and delivered from France - 3 items or names $(9 \%)$ and the Netherlands - 1 item or name $(3 \%)$ (Fig. 4$)$. 


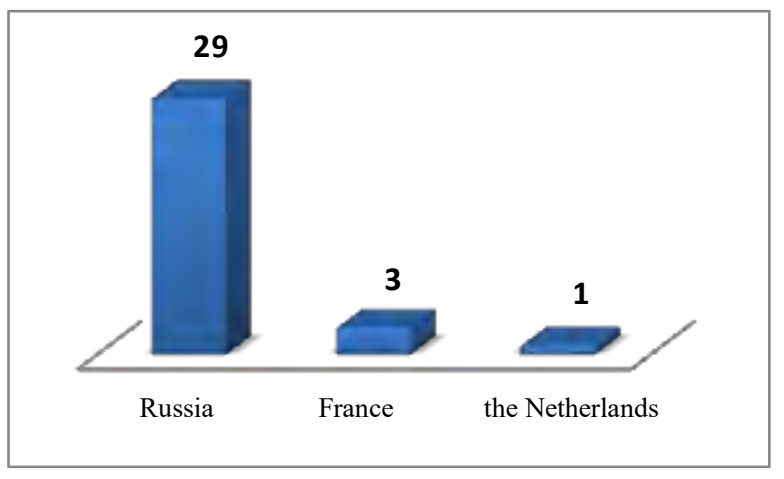

Fig. 4. Producer countries of gestagenic drugs entering the Russian market Russia; France; the Netherlands

When analyzing the manufacturers of medicinal gestagens, it was found out that the leading position is occupied by OOO NPO Api-San and NPC Skif - 8 items or names $(24 \%)$ and OOO Astropharm - 6 items or names (18\%), OOO EXPA Group - 4 items or names (12\%), SPE OOO Snow Leopard - 2 items or names $(6 \%)$, and ZAO Mosagrogen - 1 items or names $(3 \%)$ (Table 1$)$.

TABLE I. PRODUCER COMPANIES OF RUSSIAN AND FOREIGN DRUGS

\begin{tabular}{|c|c|c|}
\hline Producer companies & Item & \% \\
\hline \multicolumn{2}{|c|}{ Russian producers } \\
\hline OOO NPO Api-San & 8 & 24 \\
\hline NPC Skif & 8 & 24 \\
\hline OOO Astropharm & 6 & 18 \\
\hline OOO EXPA Group & 4 & 12 \\
\hline SPE OOO Snow Leopard & 2 & 6 \\
\hline ZAO Mosagrogen & 1 & 3 \\
\hline \multicolumn{2}{|c|}{ Foreign producers } \\
\hline Ceva Animal Health Ltd, France & 2 & 6 \\
\hline MSD Pharmaceuticals, Netherlands & 1 & 3 \\
\hline Vetoquinol S.A., France & 1 & 3 \\
\hline
\end{tabular}

Foreign producers are represented on market by Ceva Animal Health Ltd - 2 items or names (6\%), MSD Pharmaceuticals, Netherlands - 1 items or names $(3 \%)$ and Vetoquinol S.A. - 1 items or name (3\%).

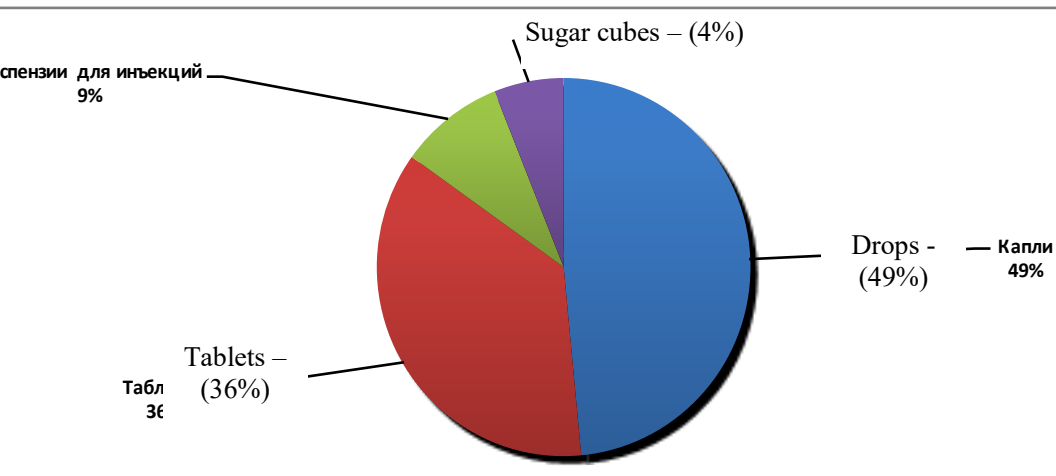

The analysis of drugs for the active substance is shown on Fig. 6.

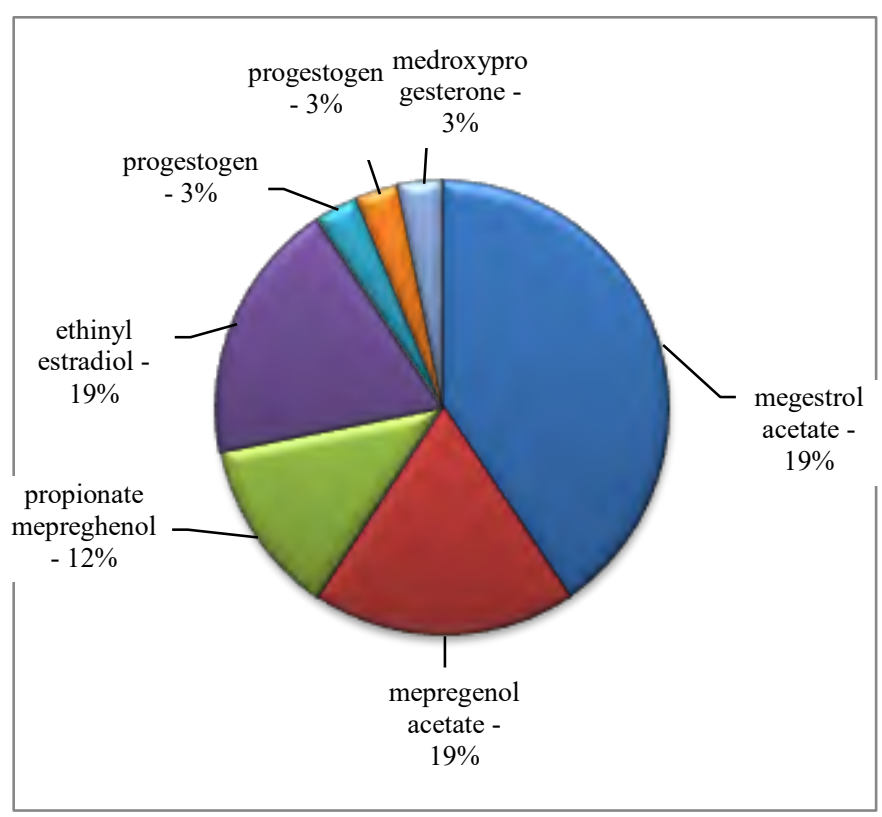

Fig. 6. Analysis of drugs for the active substance

Gestagen hormonal drugs are produced in liquid forms, i.e. drops - 16 items (49\%), suspension for injection - 3 items ( $9 \%)$, solid dosage forms, i.e. tablets -12 items (36\%) and sugar cubes -2 items (4\%) (Fig.5).

The greatest number of drugs is represented by drugs the active substance of which is megestrol acetate - 13 items or names (41\%) followed by mepregenol acetate - $6(19 \%)$, ethinyl estradiol - $6(19 \%)$, propionate mepreghenol - $4(12 \%)$, progesterone - $1(3 \%)$, progestogen - $1(3 \%)$ and medroxyprogesterone $-1(3 \%)$.

\section{CONCLUSION}

1. The reproductive disorders in cats in the city of Tyumen are widespread and amount to $12.02 \pm 0.195 \%$.

2. The structural analysis of breed predisposition to reproductive pathologies in cats showed the following: purulent endometritis was noted in cats of the Mestizo and Scottish fold breeds - 32.89\% and 25.0\%, respectively; cystic ovarian formations were observed in the Mestizo and British short-haired cats- $46.56 \%$ and $21.37 \%$, respectively; breast tumors were found in the Mestizo cats $40,00 \%$ and Sphinx cats 23,63\%, respectively. Less frequently the following diseases were recorded: pyometra of Persian cats and Maine Coons $3.94 \%$ and $2.63 \%$, respectively, polycystic ovaries in Persian and Siamese cats - $2.29 \%$ and $0.76 \%$, respectively; breast tumors in the Abyssinian cats $7.27 \%$.

Fig. 5. Gestagen hormonal drugs on Russian market

3. When analyzing the age-related predisposition, it has been established that purulent endometritis was more often diagnosed in cats aged 4 to 6 years old - $11.84 \%$; 
polycystic ovary was typical in cats from 6 to 7 years old - $12.21 \%$; breast tumors in animals older than 10 years $18.18 \%$.

4. The gestagenic drugs manufactured in Russia and abroad are used to treat the reproductive diseases. In the Russian pharmaceutical market there are 33 types (names) of gestagenic drugs. The share of domestic producers is 92 names $(91 \%)$ and the share of foreign producers is 9 names $(9 \%)$. All in all 12 manufacturers are represented on Russian market, out of this number 9 companies are Russian ones - 29 names and 3 companies are foreign ones - 4 names.

5. The gestagenic hormonal drugs are produced in liquid forms, i.e. drops - 16 types (49\%), suspension for injection - 3 types ( $9 \%$ ), solid dosage forms, i.e. tablets 12 names $(36 \%)$ and sugar cubes - 2types (4\%).

6. The most popular drugs the active substance of which is a synthetic analogue of the progestogen - megestrol acetate $-47 \%$

\section{References}

[1] G.W. England, "Hormonal manipulation of breeding in the bitch", The Veterinary Annual, 1994, Vol.34, pp.189-200

[2] Iu. O. Fedotova, S. G. Pivina, V. K. Akulova, N E. Ordian, "Effects of 8-OH-DPAT and m-CPP on depression-like behavior in prenatally stressed ovariectomized rats treated with low dose of 17beta-estradiol", Eksperimental'naia i klinicheskaia farmakologiia, 2014, Vol.77-4, pp. $10-13$

[3] D.E. Jones, J.O. Joshua, "Reproductive clinical problems in the dog", London : Wright, 2007, p.230

[4] V. V. Korkhov, E. A. Lesik, M. A. Petrosian, "Gestagenic and contraceptive activity of new synthetic progesterone analogs in experimental animals", Eksperimental'naia i klinicheskaia farmakologiia. 2005, Vol.68-1, pp. 39-41.

[5] Ya. I. Kots, O. D. Konstantinova, Yu. V. Liskova, "Effects of moexipril and estrogen-progesterone combination in women with heart failure and menopausal syndrome", Cardiovascular therapy and prevention, 2009, Vol: 8-3, pp. 62-68.

[6] A. A. Litvinov, E. V. Volotova, D. V. Kurkin, Zhurnal nevrologii i psikhiatrii, Vol. 117 (8-2), pp. 56-62.

[7] A.O. Shpakov, K.V. Derkach, V.M. Bondareva, Biomeditsinskaya Khimiya, 2011, Vol. 56-6, pp. 700-709.

[8] O.A. Zeinalov, V.V. Yaderets, T.S. Stytsenko, V.A. Andryushina, M.A Petrosyan, "Synthesis and biological activity of synthetic 17ahydroxyprogesterone derivatives", Pharmaceutical Chemistry Journal, 2012, Vol. 46, № 4, pp. 203-206.

[9] O.A. Zeynalov, S.V. Mukaseev, S.A. Parkhomenko, "Sex Barrier is a modern safe bihormonal drug for regulating sexual heat in cats and dogs", VetPharma, 2014, No.1 (17), pp. 26-29.

[10] O.A. Zeynalov, T.S. Savinova, V.A. Andryushina, "Comparative characteristics of monohormonal and bihormonal gestagen-containing drugs for suppressing behavioral manifestations of sexual heat in cats", Russian Veterinary Journal, 2017, No.2, pp.33-35.

[11] Medicinal drugs in Russia, electronic reference book Vidalretrieved from https://www.vidal.ru/

[12] A.V. Nakvasina, O.A. Stolbova, "Analysis of pathologies of reproductive system in cats in Tyumen", Modern trends in the development of science and technology, 2016, No. 11-1, pp. 109-112.

[13] O.A. Stolbova, L.N. Skosyrskikh, A.V. Nakvasina, "Diseases of reproductive system found in cats in Tyumen", Advances in modern science, 2017, Vol. 8, No. 4, pp. 210-214.

[14] V.V. Yamin, E.Yu. Skladneva, "Histological features of uterus as a function of estrous phase of cats' cycle", Modern problems of science and education, 2015, No. 1, pp. 56-59.

[15] V.V. Yamin, "Echographic characteristics of uterus in cats in case of pathologie",. Bulletin of the Khakass State University named after. N.F. Katanova, 2015, No. 13, pp. 125-128. 